\title{
Dissecting the Structural Organization of Multiprotein Amyloid Aggregates Using a Bottom-Up Approach
}

\author{
Himanshu Chaudhary, Sebastian W. Meister, Henrik Zetterberg, John Löfblom, and Christofer Lendel*
}

Cite This: https://dx.doi.org/10.1021/acschemneuro.0c00110

Read Online

\begin{abstract}
Deposition of fibrillar amyloid $\beta(\mathrm{A} \beta)$ in senile plaques is a pathological signature of Alzheimer's disease. However, senile plaques also contain many other components, including a range of different proteins. Although the composition of the plaques can be analyzed in post-mortem tissue, knowledge of the molecular details of these multiprotein inclusions and their assembly processes is limited, which impedes the progress in deciphering the biochemical mechanisms associated with $\mathrm{A} \beta$ pathology. We describe here a bottom-up approach to monitor how proteins from human cerebrospinal fluid associate with $\mathrm{A} \beta$ amyloid fibrils to form plaque particles. The method combines flow cytometry and mass spectrometry proteomics and allowed us to identify and quantify 128 components of

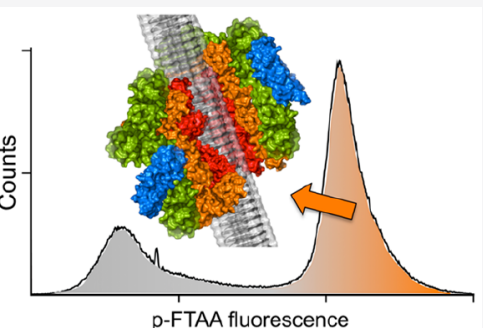
the captured multiprotein aggregates. The results provide insights into the functional characteristics of the sequestered proteins and reveal distinct interactome responses for the two investigated $\mathrm{A} \beta$ variants, $\mathrm{A} \beta(1-40)$ and $\mathrm{A} \beta(1-42)$. Furthermore, the quantitative data is used to build models of the structural organization of the multiprotein aggregates, which suggests that $\mathrm{A} \beta$ is not the primary binding target for all the proteins; secondary interactions account for the majority of the assembled components. The study elucidates how different proteins are recruited into senile plaques and establishes a new model system for exploring the pathological mechanisms of Alzheimer's disease from a molecular perspective.
\end{abstract}

KEYWORDS: amyloid, Alzheimer's disease, amyloid $\beta$, protein-protein interaction, flow cytometry

\section{INTRODUCTION}

Neurodegenerative disorders are among the major medical challenges for the future. A pathological signature that is shared by several of these conditions (including, e.g., Alzheimer's and Parkinson's diseases) is the accumulation of certain proteins in amyloid structures in the central nervous system. ${ }^{1}$ Alzheimer's disease $(\mathrm{AD})$ is associated with two types of protein inclusions: intracellular neurofibrillary tangles made mainly from hyperphosphorylated protein tau and extracellular senile plaques with amyloid $\beta(\mathrm{A} \beta)$ as key building block. ${ }^{2}$ Accumulation of $\mathrm{A} \beta$ in cerebral vasculature leading to cerebral amyloid angiopathy is also observed in the majority of $\mathrm{AD}$ cases. $^{3}$ Notably, senile plaques, as well as neurofibrillary tangles and most other pathological protein inclusions, do not only consist of a single amyloid-forming protein. ${ }^{4,5}$ These deposits contain a range of different components, including other proteins, lipids, carbohydrates, and metal ions, ${ }^{5}$ and all plaques do not contain exactly the same constituents. ${ }^{6}$ A variety of different proteins have been found to be associated with senile plaques derived from brain autopsy of $\mathrm{AD}$ patients using, e.g., immunohistochemistry, ${ }^{7-10}$ laser microdissection proteomics approaches $^{6,11,12}$ or spatially targeted optical microproteomics. ${ }^{13}$ These studies have provided valuable knowledge about the $\mathrm{AD}$ pathology, but they are not able to distinguish between components that are integral parts of the plaques and those that are more loosely associated with the deposits or provide insights in the dynamics of the plaque's composition during build-up.

In a previous study, we reported that stabilized prefibrillar $\mathrm{A} \beta$ aggregates (protofibrils) are decorated with a range of human proteins when introduced in serum or cerebrospinal fluid (CSF) ${ }^{14}$ Our findings emphasize that the pathological processes related to $\mathrm{A} \beta$ may not be fully understood from studies of experimental systems lacking the critical protein binding partners. This is in line with the pioneering work from Olzscha et al. which showed that a range of essential proteins are sequestered by artificial amyloid aggregates when expressed in a human cell model. ${ }^{15}$ More recently, it has also been reported that amyloid fibrils of various origin attract "coronas" of binding proteins when introduced into a biological environment. ${ }^{16-18}$ The role of protein coronas for the biological response is established for synthetic nanoparticles, ${ }^{19}$ and it is now becoming evident that this phenomenon is also highly relevant to understand the biological activities of biomolecular nanoparticles, such as amyloid structures or virus particles. ${ }^{20}$ From a more fundamental perspective, it can

Received: February 26, 2020

Accepted: April 21, 2020

Published: April 22, 2020 
be noted that any pathogenic process initiated by an amyloid aggregate must involve interactions between the aggregate and other (bio)molecules. Hence, a detailed understanding of how the multiprotein aggregates that eventually develop into senile plaques are formed is crucial in order to achieve a molecular description of the pathological mechanisms.

Here, we present a bottom-up approach to isolate, identify, and quantitatively evaluate the components of the multiprotein aggregates that are formed around amyloid fibrils of $\mathrm{A} \beta(1-40)$ and $\mathrm{A} \beta(1-42)$, respectively, when introduced in human CSF (Figure 1) These are the two main variants of $\mathrm{A} \beta$, with $\mathrm{A} \beta(1-$

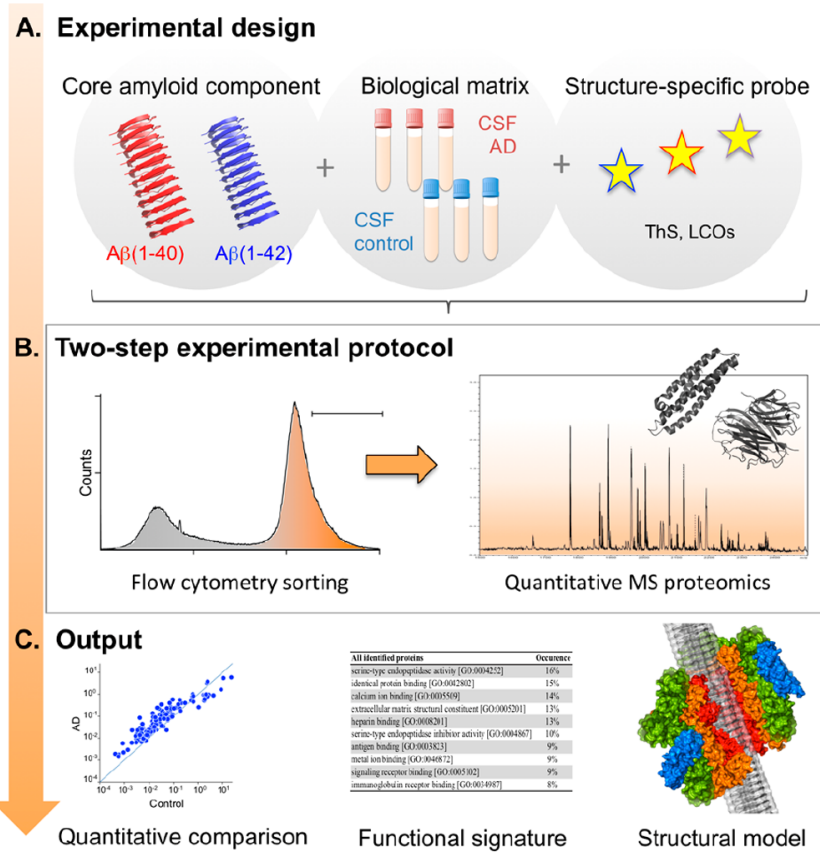

Figure 1. Schematic overview of the presented approach. (A) Experiments are designed by selecting different combinations of amyloid core component (i.e., fibrils from different peptides or with specific morphologies), biological matrix, and structure specific amyloid probes. (B) Selected components are mixed and multiprotein aggregates are isolated by flow cytometry. The components of these aggregates are then identified and quantified using MS. (C) We demonstrate how the results can be used for quantitative comparison of the components selected in the experimental design, provide functional signatures of the assembled complexes, and provide the basis for a building a structural model of the multiprotein aggregates.

42 ) being the more aggregation prone peptide. ${ }^{2}$ CSF is used as model environment for the formation of senile plaques. Although this is not exactly the same environment as the brain parenchyma, CSF communicates freely with the brain interstitial fluid, which is the matrix in which the plaques are formed, ${ }^{21}$ and $\mathrm{A} \beta$ levels in CSF have been shown to reflect brain amyloid load. ${ }^{22}$ Clearly, the time frames of the study are also different than the cumulative buildup of plaques in Alzheimer patients, suggesting that the results primarily describe the composition of particles that may be early seeds for senile plaques. To explore if the disease progression affected the composition of the multiprotein aggregates, we compare CSF samples from $\mathrm{AD}$ patients and controls.

The employed method is based on detection and sorting of the aggregates by flow cytometry (FC). ${ }^{23,24} \mathrm{~A}$ similar approach was recently used to identify the protein components of "plaque particles" formed by spiking human serum with soluble
A $\beta, \alpha$-synuclein, tau, or cholesterol aggergates. ${ }^{25}$ We have validated and further developed the methodology, which allows us to carry out a quantitative analysis of the compositions of the isolated multiprotein aggregates and propose a preliminary structural model.

\section{RESULTS AND DISCUSSION}

Preparation of $\mathbf{A} \boldsymbol{\beta}$ Amyloid Aggregates. Recombinantly produced $\mathrm{A} \beta(1-40)$ and $\mathrm{A} \beta(1-42)$ were separately incubated at $37^{\circ} \mathrm{C}$ for $48 \mathrm{~h}$ to produce fibrillar amyloid aggregates. Using recombinant peptides excluded the risk of contamination by other proteins that is associated with in vivo-derived $\mathrm{A} \beta$ samples. We chose to apply the same incubation conditions and incubation times, which we can easily control, for the two peptide variants rather than attempting to compare specific fibrillar morphologies, which are difficult to assess in a quantitative manner. After $48 \mathrm{~h}$, fibrillation reached completion for both peptide variants, ${ }^{26,27}$ and the presence of amyloid fibrils was confirmed by enhanced thioflavin T (ThT) fluorescence, circular dichroism (CD) spectra indicative of $\beta$ sheet structure, and the observation of fibrillar structures by atomic force microscopy (AFM) (SI Figure S1).

FC Detection of $\mathbf{A} \boldsymbol{\beta}$ Aggregates in Biological Samples. Method development and validation were carried out using human serum. We first verified that $\mathrm{A} \beta$ amyloid aggregates bound to thioflavin $S$ (ThS) can be detected by FC as previously reported by Madasamy et al. ${ }^{25}$ The presence of particles is confirmed by the scattering plots (Figure 2A) and by a much higher particle count rate for samples containing $\mathrm{A} \beta$ compared to buffer-only samples (data not shown). Moreover, the $\mathrm{A} \beta$-containing samples exhibited a distinct shift in fluorescence intensity compared to samples with $\mathrm{ThS}$ in serum (Figure 2), showing that the aggregates can be identified even in the complex background of a biological sample. We then used the described approach to isolate multiprotein aggregates for MS identification of binding proteins in human serum. In total, 126 and 125 binding proteins were found in samples spiked with $\mathrm{A} \beta(1-40)$ and $\mathrm{A} \beta(1-42)$ fibrils, respectively (SI Table S1).

FC and Pull-Down Experiments Are Complementary Methods. As a comparison we also carried out pull-down experiments using the same methodology as previously used for $\mathrm{A} \beta(1-42)$ protofibrils $^{14}$ and amyloid fibrils. ${ }^{28}$ In these samples, 122 and 107 proteins were identified for $\mathrm{A} \beta(1-40)$ and $\mathrm{A} \beta(1-42)$, respectively (SI Table S1). Notably, the overlap between the proteins identified with FC sorting and the pull-down isolation is only about one-third (Figure 3C,D), indicating that the two methods provide complementary results. We also observed that with the FC method, $76 \%$ (i.e., 108 proteins) of the total number of identified proteins were found in both $\mathrm{A} \beta(1-40)$ and $\mathrm{A} \beta(1-42)$ samples, while the corresponding number for the pull-down approach is $25 \%$. Out of these $25 \%$ (i.e., 44 proteins), $84 \%$ ( 37 proteins) are also found in the control experiments with glycine-coated beads (Figure 3A), suggesting that nonspecific binding affects the results for the pull-down approach, which makes quantitative analysis difficult. The control experiment for FC would be to isolate particles from a serum sample without added $\mathrm{A} \beta$ using the same sorting gates. It is evident from Figure $2 \mathrm{~B}$ that essentially no such particles are detected.

Moreover, to validate the reproducibility of the methods we repeated the experiment three times with the same serum sample in separate analyses (referred to as the second batch in 
A

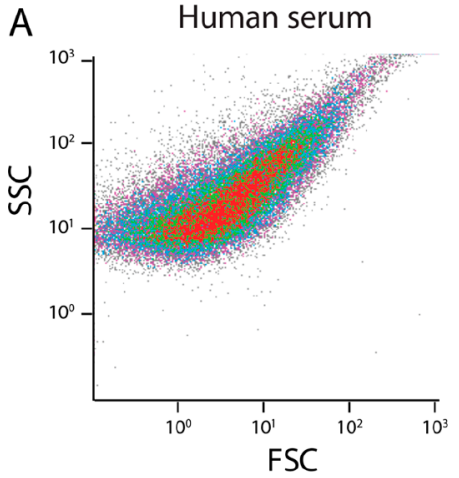

$A \beta(1-40)$ human serum

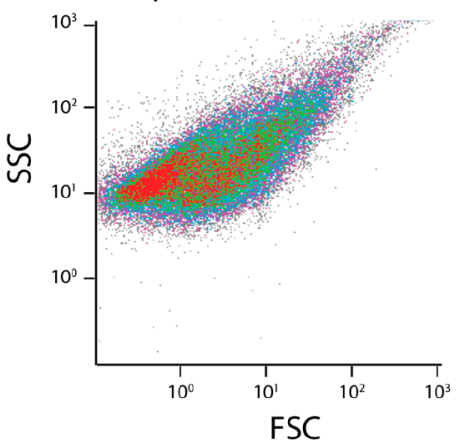

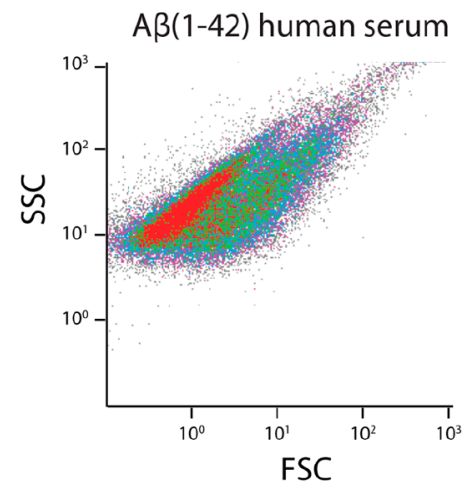

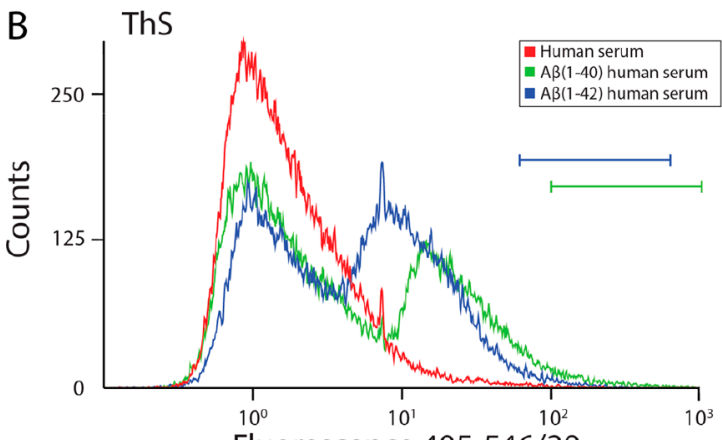

Fluorescence 405-546/20

Figure 2. FC detection of $\mathrm{A} \beta$ aggregates in human serum. (A) Density plots from FC analysis of human serum only (left) and serum with added $\mathrm{A} \beta$ aggregates. Forward scatter intensity (FSC) is on the $x$-axis and side scatter intensity (SSC) on the $y$-axis. (B) Overlay of ThS fluorescence intensity histograms from FC analysis of samples with ThS (same runs as in panel A). The blue and green horizontal lines indicate the sorting gates used to isolate samples for MS analysis.
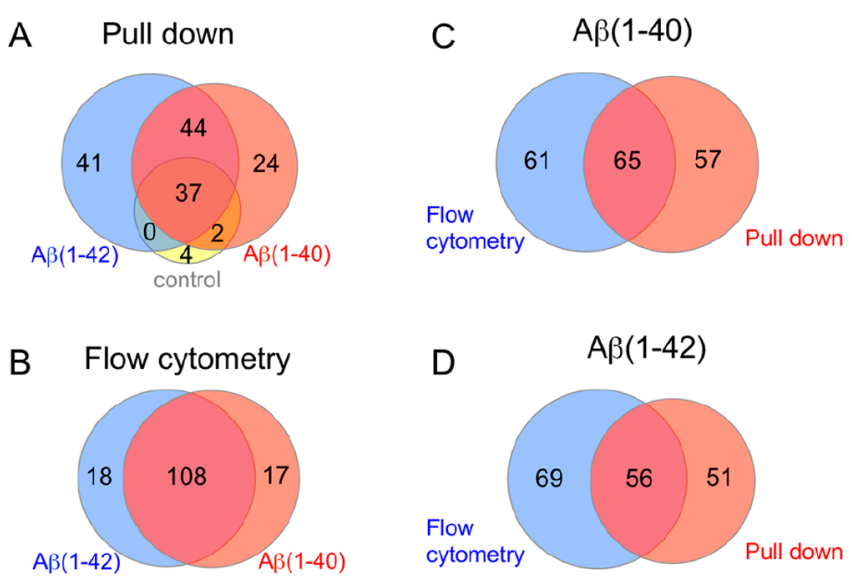

Figure 3. Comparison between pull-down and FC isolation of multiprotein aggregates. (A, B) Venn diagrams showing the number of proteins identified with the pull-down method for $\mathrm{A} \beta(1-40)$, $\mathrm{A} \beta(1-42)$, and glycine (control) coated magnetic beads, respectively (A), and the number of proteins identified with the FC sorting of $\mathrm{A} \beta(1-40)$ and $\mathrm{A} \beta(1-42)$ spiked samples, respectively (B). (C, D) Comparisons of the proteins identified in association with $\mathrm{A} \beta(1-40)$ (C) and $\mathrm{A} \beta(1-42)$ (D) with the two methods. Among the proteins that were identified by both methods, 30 and 32 proteins were also found in the pull-down control for $\mathrm{A} \beta(1-40)$ (C) and $\mathrm{A} \beta(1-42)$ (D), respectively.

the Methods section). With the FC method, $65 \%$ of the identified proteins were found in all three samples, while $20 \%$ were only found in one sample. For the pull-down approach, $37 \%$ were found in all three samples and $34 \%$ were only found in one sample. This indicates that the reproducibility of the FC method is higher than for the pull-down method.
Sensitivity Is Improved with LCO Probes. The experiments carried out so far demonstrated that ThS can detect amyloid structures. However, the use of newly developed amyloid probes could potentially improve both the sensitivity and the specificity of the method. Luminescent conjugated oligothiophenes (LCOs) is a group of compounds that have emerged as excellent probes of amyloid structures with the ability to distinguish between different classes of aggregates. $^{29}$ We examined three different LCOs in the FC setup: p-FTAA, which is a general amyloid ligand with the ability to detect most types of aggregates but with a higher sensitivity than ThT and ThS; ${ }^{30}$ q-FTAA-CN, with a higher affinity for human brain-derived aggregates compared to synthetic fibrils; ${ }^{31}$ and bTVBT2, which selectively recognizes tau aggregates in brain tissue. ${ }^{32}$ From the results with serum samples spiked with $\mathrm{A} \beta(1-40)$ or $\mathrm{A} \beta(1-42)$ fibrils, we find that both p-FTAA and q-FTAA-CN provide improved separation between the amyloid aggregates and the serum background in the fluorescence distribution profiles compared to ThS (Figure 4). bTVBT2, on the other hand, shows a trend in the opposite direction, which is in line with the assumption that the multiprotein aggregates are formed around $\mathrm{A} \beta$ and not tau. Based on these results, we decided to use p-FTAA as probe for the experiments with human CSF samples.

Quantitative MS of CSF Samples. The formation of multiprotein aggregates was explored in human CSF samples from $\mathrm{AD}$ patients and non- $\mathrm{AD}$ controls (seven of each, $\mathrm{SI}$ Table S2) spiked with either $A \beta(1-40)$ or $A \beta(1-42)$ fibrils. The developed FC protocol was employed to isolate multiprotein aggregates for MS analysis from a total of 28 samples. Representative fluorescence distribution profiles are shown in SI Figure S2. Quantitative data were obtained 

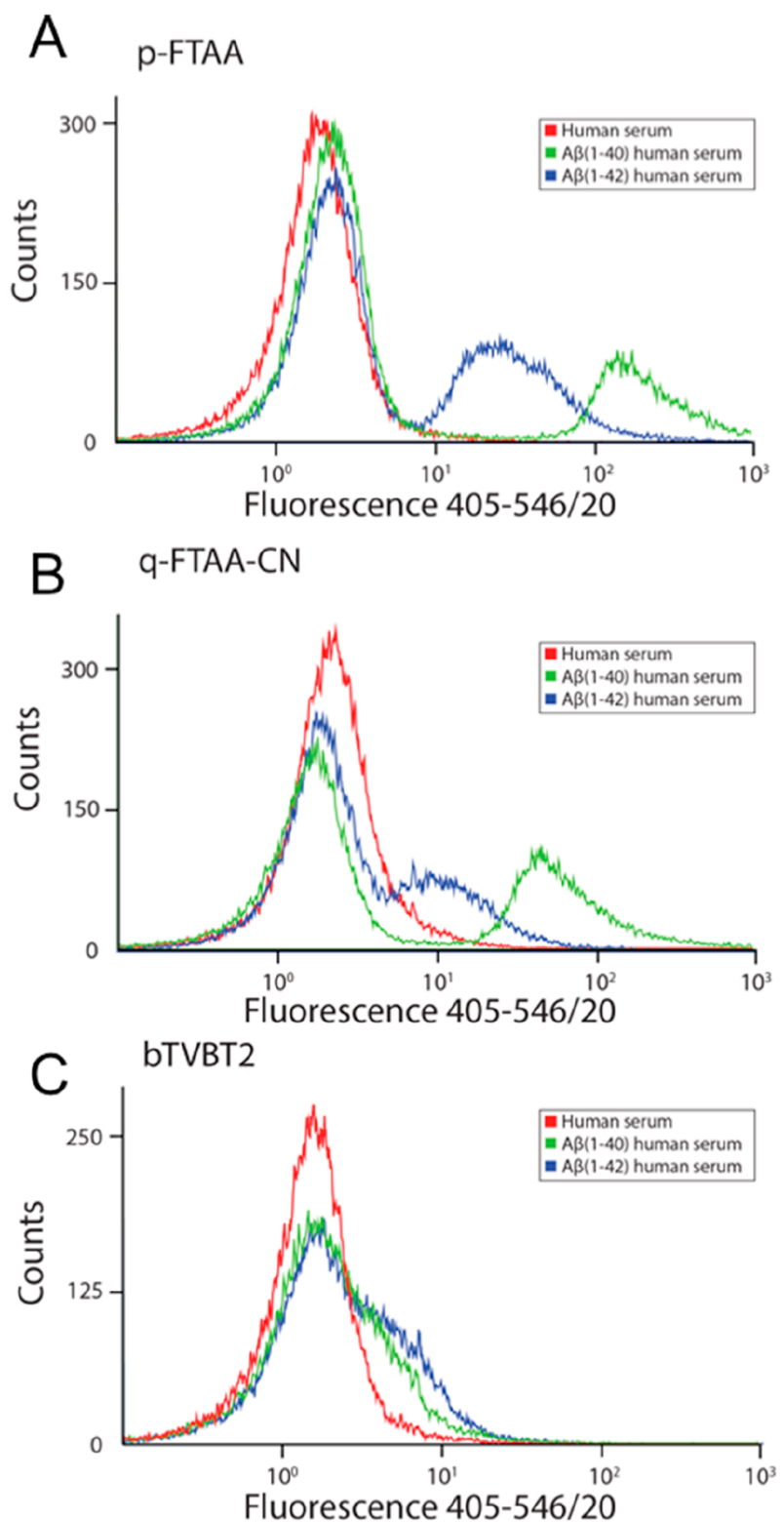

Figure 4. Overlay of LCO fluorescence intensity histograms from flow cytometry analysis of human serum only and serum with added $\mathrm{A} \beta$ aggregates. (A) p-FTAA probe. (B) q-FTAA-CN probe. (C) bTVBT2 probe.

through tandem mass tag (TMT) labeling, and the abundance values were normalized to the detected amount of $\mathrm{A} \beta$ in each sample. In total, 128 unique proteins, including $A \beta$, were detected and quantified (Table 1). The majority of the proteins (at least $82 \%$ ) have previously been identified in senile plaques using microdissection techniques. ${ }^{6,12}$ This supports our hypothesis that the presented results provide information about the assembly of senile plaques. In comparison with previous pull-down studies, we note that $58 \%$ of the identified proteins in our study overlap with the proteins reported to bind to $\mathrm{A} \beta(1-42)$ fibrils, ${ }^{28}$ while $35 \%$ were also found to bind to prefibrillar aggregates modeled by $\mathrm{A} \beta(1-42) \mathrm{cc}$ protofibrils. ${ }^{14}$ The list (Table 1) contains several known amyloid precursor proteins, ${ }^{33}$ e.g., transthyretin, $\beta 2$-microglobulin, gelsolin, and apolipoproteins, which is in agreement with a previous study of the interactomes of selected amyloid fibrils. ${ }^{16}$ There are also proteins that have been suggested as CSF biomarkers for $\mathrm{AD}, 34,35$ e.g., chitinase-3-like protein 1, osteopontin, cystatin $\mathrm{C}$, hemopexin, and zinc $\alpha$-2 glycoprotein. Apolipoprotein E (apoE) and clusterin (apoJ), that are recognized genetic risk factors of $\mathrm{AD}^{2}$, are both among the most abundant proteins (Figure 5 and Table 1).

The abundances of the proteins in CSF samples from $\mathrm{AD}$ patients and controls, respectively, are compared in Figure 5. Statistical analysis revealed one protein that is significantly enriched in the $\mathrm{AD}$ samples with $\mathrm{A} \beta(1-40)$ added (pyruvate kinase, $p=8.8 \times 10^{-5}$ ) and two proteins that are significantly enriched in the $\mathrm{AD}$ samples with $\mathrm{A} \beta(1-42)$ added (alpha-2HS-glycoprotein with $p=0.030$ and prothrombin with $p=$ $0.024)$. Increase in pyruvate kinase activity has been observed in the frontal and temporal cortex of $\mathrm{AD}$ brains ${ }^{36}$ and the rabbit version of the enzyme inhibits the aggregation of $\mathrm{A} \beta(1-$ 40). ${ }^{37}$ Plasma levels of alpha-2-HS-glycoprotein has been found to be lower in $\mathrm{AD}$ patients than controls, potentially suggesting that the protein is sequestered in amyloid inclusions. ${ }^{38}$ Prothrombin and its final product, thrombin, seems to be central in neurodegenerative processes associated with brain injury or disease. ${ }^{39}$ A dysfunctional blood-brain barrier leads to (pro)thrombin entering the CNS and reaches high levels, ${ }^{39}$ which might be related to the enrichment in $\mathrm{AD}$ samples. Prothrombin is also involved in tau proteolysis, ${ }^{40}$ a process that is reduced for phosphorylated tau.

Functional Analysis of the Binding Proteins. Comparison of the abundances with selected properties of the proteins (such as size, charge, predicted solubility, or propensity to form amyloid) displayed no obvious correlations (SI Figure S3). Hence, we conclude that the binding of the identified proteins is not only a reflection of their physicochemical properties. This is in line with the results for the corona of IAPP amyloid fibrils. ${ }^{18}$ Instead, we analyzed the list of identified proteins in terms of gene ontology (GO) annotations to explore the functional characteristics of the proteins bound to the $\mathrm{A} \beta$ amyloid aggregates. The most frequently occurring molecular function among all 127 binding proteins is serine-type endopeptidase activity (18\%) followed by identical protein binding (15\%) and calcium ion binding (14\%) (SI Table S4). If we focus only on the $10 \%$ of the proteins with the highest average abundances in each sample type (SI Table S4), we find that identical protein binding is the most common function (39-46\%) followed by amyloid- $\beta$ binding (18\%). The finding that several of the high abundance proteins are known $\mathrm{A} \beta$ binding proteins provide some validation of the results. The results also indicate that proteins with an intrinsic ability to form homomultimeric structures might be more prone to bind to amyloid aggregates than what other proteins would be. The list of enriched functions among the top $10 \%$ binders also contains functionality related to lipid/cholesterol binding, which is in line with the fact that these molecules are often found in senile plaques. ${ }^{5}$ For GO biological processes, the most frequent annotation among all the identified proteins is cellular protein metabolic process $(21 \%)$, which is also the most frequent in the top $10 \%$ abundant proteins $(46-62 \%)$ (SI Table S3). Hence, there is a direct link between the sequestering of proteins to the amyloid structures and changes in protein metabolism. The majority of the most frequently occurring processes are related to protein processing (e.g., cellular protein metabolic process or post-translational protein modification), defense mechanisms (e.g., immune response or complement activation), or vesicle transport (e.g., platelet- or neutrophil degranulation) (SI Table S3). GO cellular 
Table 1. Proteins Identified by MS in $\mathrm{CSF}^{a}$

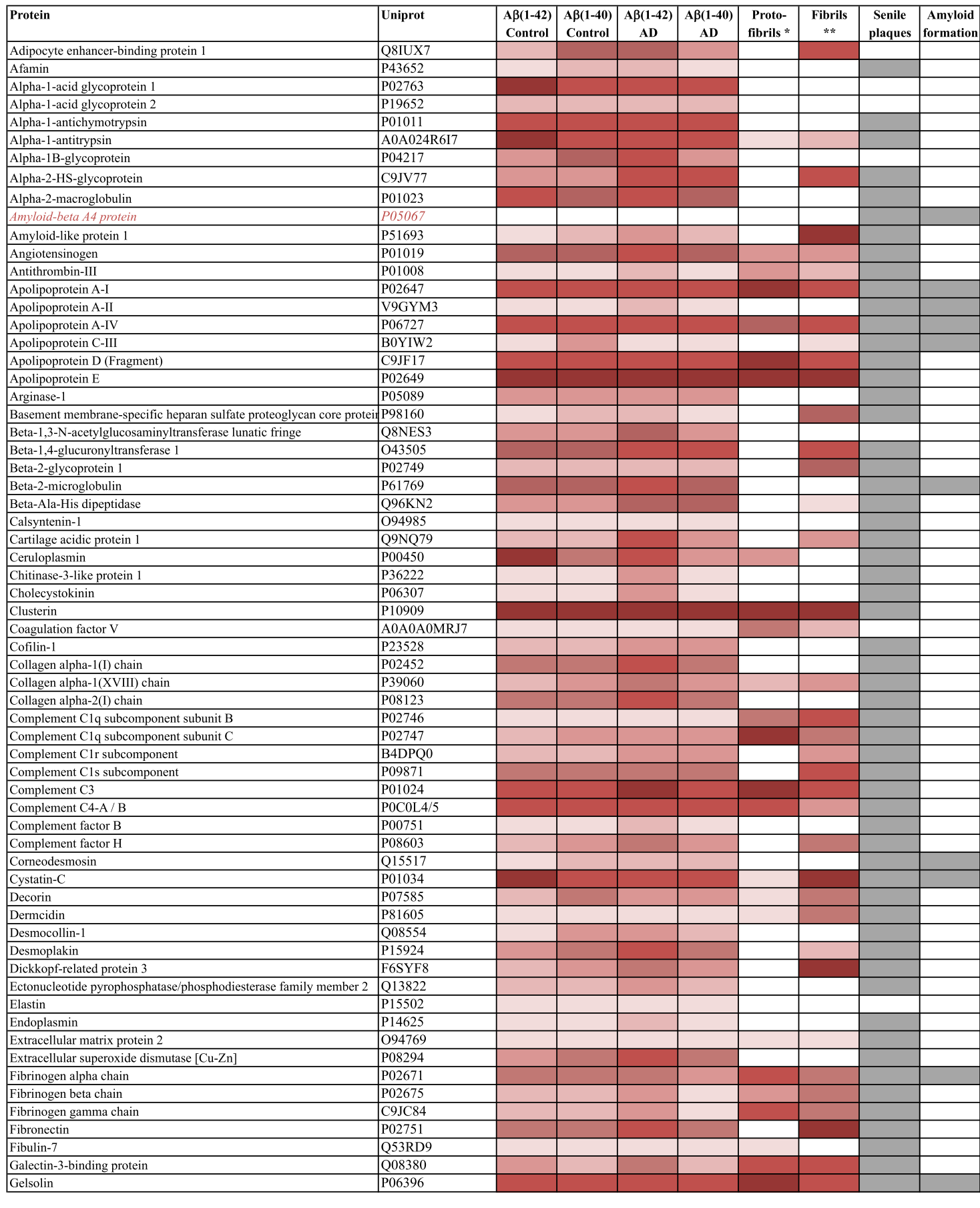




\section{Table 1. continued}

\begin{tabular}{|c|c|c|c|c|c|c|c|c|c|}
\hline Protein & Uniprot & $\begin{array}{c}\mathbf{A} \beta(1-42) \\
\text { Control } \\
\end{array}$ & \begin{tabular}{|c|}
$\mathbf{A} \beta(1-40)$ \\
Control \\
\end{tabular} & \begin{tabular}{|c|}
$\mathbf{A} \beta(1-42)$ \\
$\mathrm{AD}$
\end{tabular} & \begin{tabular}{|c|}
$\mathbf{A} \beta(1-40)$ \\
$\mathrm{AD}$
\end{tabular} & \begin{tabular}{|c|}
$\begin{array}{c}\text { Proto- } \\
\text { fibrils * }\end{array}$ \\
\end{tabular} & $\begin{array}{c}\text { Fibrils } \\
* *\end{array}$ & \begin{tabular}{|c|}
$\begin{array}{c}\text { Senile } \\
\text { plaques }\end{array}$ \\
\end{tabular} & $\begin{array}{c}\text { Amyloid } \\
\text { formation }\end{array}$ \\
\hline Growth arrest-specific protein 6 & Q14393 & & & & & & & & \\
\hline Haptoglobin & H0Y300 & & & & & & & & \\
\hline Haptoglobin-related protein & P00739 & & & & & & & & \\
\hline Hemoglobin subunit alpha & P69905 & & & & & & & & \\
\hline Hemoglobin subunit beta & P68871 & & & & & & & & \\
\hline Hemopexin & P02790 & & & & & & & & \\
\hline Heparin cofactor 2 & P05546 & & & & & & & & \\
\hline Histidine protein methyltransferase 1 homolog & O95568 & & & & & & & & \\
\hline Histidine-rich glycoprotein & P04196 & & & & & & & & \\
\hline Ig heavy constant alpha 1 & $\mathrm{P} 01876$ & & & & & & & & \\
\hline Ig heavy constant alpha 2 & P01877 & & & & & & & & \\
\hline Ig heavy constant gamma 1 & $\mathrm{P} 01857$ & & & & & & & & \\
\hline Ig heavy constant gamma 2 & P01859 & & & & & & & & \\
\hline Ig heavy constant gamma 4 & P01861 & & & & & & & & \\
\hline Ig heavy variable $6-1$ & A0A0B4J1U7 & & & & & & & & \\
\hline Ig kappa constant & P01834 & & & & & & & & \\
\hline Ig kappa variable 3-20 / 3D-20 & P01619 & & & & & & & & \\
\hline Ig lambda constant 1 / Ig lambda-like polypeptide 5 & P0CG04 & & & & & & & & \\
\hline Ig lambda constant $2 / 3$ & P0DOY $2 / 3$ & & & & & & & & \\
\hline Ig lambda constant $6 / 7$ & P0CF74 / A0M8Q6 & & & & & & & & \\
\hline Ig lambda variable 1-47 & P01700 & & & & & & & & \\
\hline Inter-alpha-trypsin inhibitor heavy chain $\mathrm{H} 1$ & P19827 & & & & & & & & \\
\hline Inter-alpha-trypsin inhibitor heavy chain $\mathrm{H} 4$ & Q14624 & & & & & & & & \\
\hline Kallikrein-6 & Q92876 & & & & & & & & \\
\hline Kininogen-1 & $\mathrm{P} 01042$ & & & & & & & & \\
\hline L-lactate dehydrogenase A chain & P00338 & & & & & & & & \\
\hline Latent-transforming growth factor beta-binding protein 4 & Q8N2S1 & & & & & & & & \\
\hline Mannosyl-oligosaccharide 1,2-alpha-mannosidase IA & P33908 & & & & & & & & \\
\hline Microfibril-associated glycoprotein 4 & K7ES70 & & & & & & & & \\
\hline Mimecan & P20774 & & & & & & & & \\
\hline Monocyte differentiation antigen CD14 & P08571 & & & & & & & & \\
\hline Neural cell adhesion molecule 1 & A0A087WV75 & & & & & & & & \\
\hline Neurosecretory protein VGF & O15240 & & & & & & & & \\
\hline Olfactomedin-like protein 3 & Q9NRN5 & & & & & & & & \\
\hline Osteomodulin & Q99983 & & & & & & & & \\
\hline Osteopontin & P10451 & & & & & & & & \\
\hline Phosphoglycerate kinase 1 & $\mathrm{P} 00558$ & & & & & & & & \\
\hline Phospholipid transfer protein & P55058 & & & & & & & & \\
\hline Pigment epithelium-derived factor & P36955 & & & & & & & & \\
\hline Plasma protease $\mathrm{C} 1$ inhibitor & E9PGN7 & & & & & & & & \\
\hline Procollagen C-endopeptidase enhancer 1 & Q15113 & & & & & & & & \\
\hline Prolargin & P51888 & & & & & & & & \\
\hline ProSAAS & Q9UHG2 & & & & & & & & \\
\hline Prosaposin & C9JIZ6 & & & & & & & & \\
\hline Prostaglandin-H2 D-isomerase & P41222 & & & & & & & & \\
\hline Proteoglycan 4 & Q92954 & & & & & & & & \\
\hline Prothrombin & P00734 & & & & & & & & \\
\hline Prothymosin alpha & P06454 & & & & & & & & \\
\hline Pyruvate kinase (Fragment) & H3BTN5 & & & & & & & & \\
\hline Secreted frizzled-related protein 3 & Q92765 & & & & & & & & \\
\hline Secretogranin-1 & P05060 & & & & & & & & \\
\hline Selenoprotein $\mathrm{P}$ & $\mathrm{P} 49908$ & & & & & & & & \\
\hline Serotransferrin & $\mathrm{P} 02787$ & & & & & & & & \\
\hline SPARC-like protein 1 & Q14515 & & & & & & & & \\
\hline Spondin-1 & Q9HCB6 & & & & & & & & \\
\hline Sushi repeat-containing protein SRPX & P78539 & & & & & & & & \\
\hline Testican-1 & Q08629 & & & & & & & & \\
\hline Thioredoxin & P10599 & & & & & & & & \\
\hline Transthyretin & P02766 & & & & & & & & \\
\hline Uncharacterized protein & E7ETN3 & & & & & & & & \\
\hline Vitamin D-binding protein & D6RF35 & & & & & & & & \\
\hline Vitamin K-dependent protein S & P07225 & & & & & & & & \\
\hline Vitronectin & P04004 & & & & & & & & \\
\hline Zinc-alpha-2-glycoprotein & P25311 & & & & & & & & \\
\hline
\end{tabular}

${ }^{a}$ Abundances (normalized) indicated by the color, from light red (low) to dark red (high). The binding to A $\beta$ protofibrils and fibrils in previous (pull-down) studies are also shown with color-coding indicating in how many samples the proteins were found. In addition, the appearance in senile plaques (ex vivo samples) and the ability to form amyloid are indicated. *Ref $14 . * *$ Ref 28.

components is, as expected, strongly associated with extracellular space as CSF was used as biological sample (SI Table S5).

GO was also explored for the $10 \%$ most enriched proteins in either AD CSF or control CSF (SI Tables S6-S8). Interestingly, these lists highlight a different set of functional characteristics, except for the GO cellular components, which are essentially the same. For the GO biological process, the most enriched proteins lack the most common annotations found for the high abundance proteins, including cellular protein metabolic process, neutrophil degranulation, and all annotations and complement-related processes. Instead, negative regulation of blood coagulation and positive regulation of neurofibrillary tangle assembly, which are both highly relevant for $\mathrm{AD}$ pathology, are found among the top annotations. One should note that it is not the processes per se that are enriched but rather various proteins related to the processes. Hence, it is not strange that these annotations 

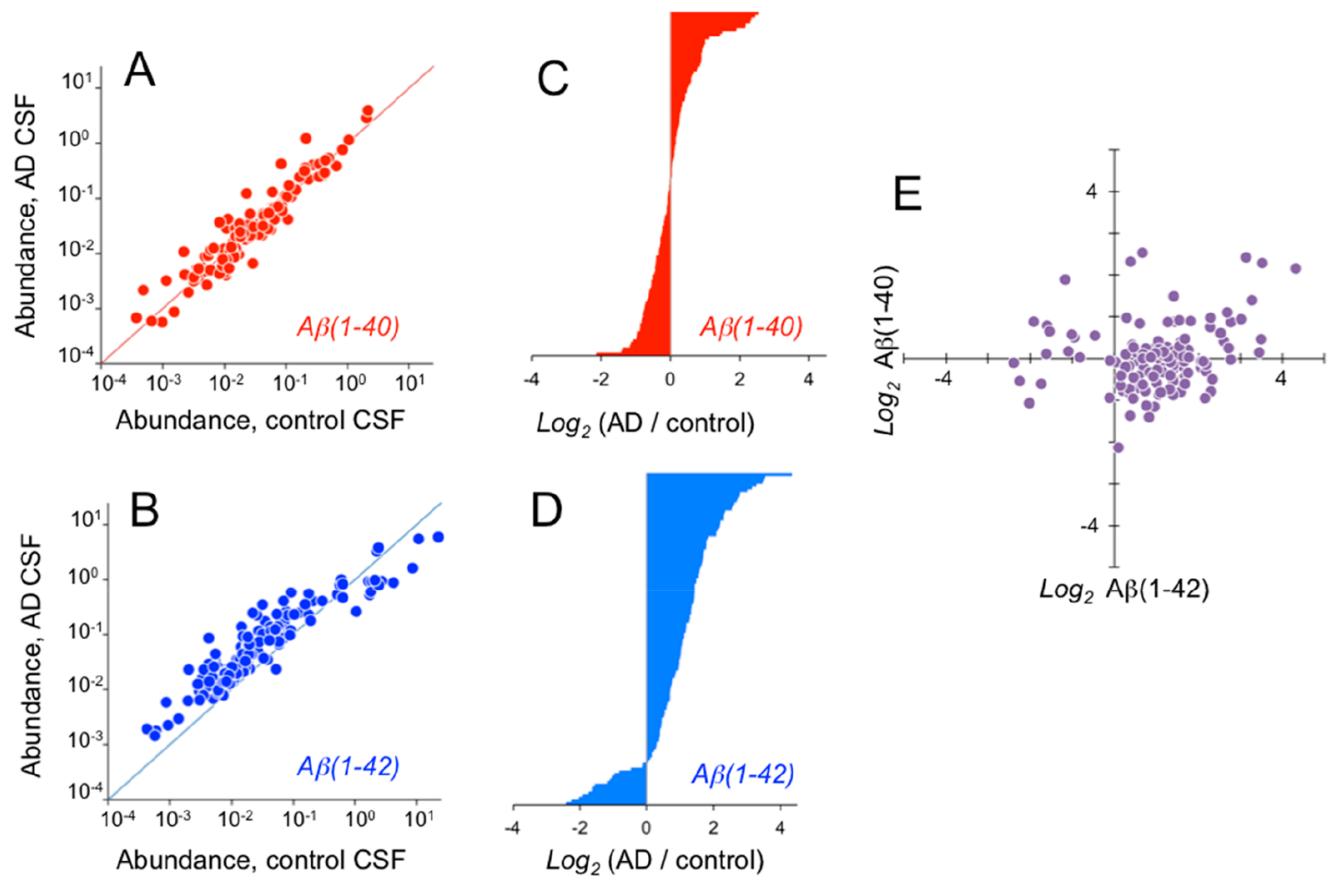

Figure 5. $(\mathrm{A}, \mathrm{B})$ Comparison of mean abundances in $\mathrm{AD}$ and control CSF samples, respectively, with the addition of $\mathrm{A} \beta(1-40)$ fibrils $(\mathrm{A})$ and A $\beta(1-42)$ fibrils (B). The diagonal lines are shown to guide the eye. (C,D) Comparison of mean abundances in AD and control CSF samples, respectively, shown as the ratio between $\mathrm{AD}$ and control (on a $\log _{2}$ scale). The data is displayed from lowest to highest values for proteins found in samples with $\mathrm{A} \beta(1-40)$ fibrils (C) and $\mathrm{A} \beta(1-42)$ fibrils (D). (E) Comparison the $\log _{2}$ ratios for $\mathrm{A} \beta(1-40)$ and $\mathrm{A} \beta(1-42)$.

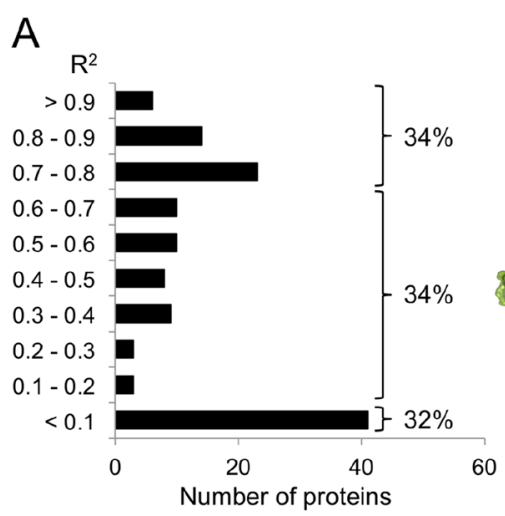

\section{B}

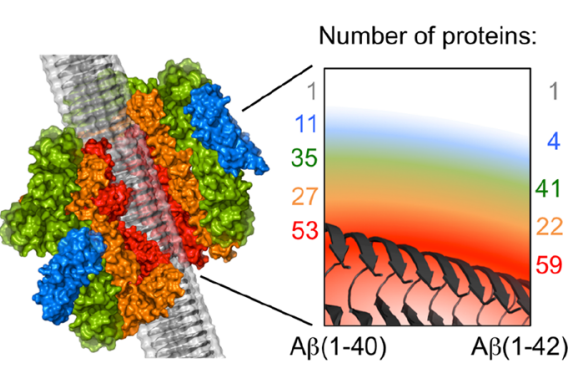

Figure 6. (A) Distribution of $R^{2}$-values for the correlations between the binding proteins and A $\beta$ (in all analyzed CSF samples). (B) Model for the architecture of the multiprotein aggregates based on pairwise correlations between all proteins. The numbers indicate how many proteins that are found in each "layer". For $\mathrm{A} \beta(1-42)$, the number in blue includes both the fourth and fifth layers. All 14 samples for each $\mathrm{A} \beta$ variant were included in the analysis. The complete list of proteins in each layer is found SI Table S10.

appear among enriched proteins in both $\mathrm{AD}$ and control CSF. Notably, for GO molecular function, calcium ion binding appears as the most common annotation among the proteins enriched in the $\mathrm{AD}$ CSF samples (but not in control) for both $\mathrm{A} \beta(1-40)$ and $\mathrm{A} \beta(1-42)$. This may indeed be related to the fact that dysfunctional calcium homeostasis is a part of the $\mathrm{AD}$ pathology. $^{2}$

Differences between $A \beta(1-40)$ and $A \beta(1-42)$. Figure $5 \mathrm{~A}, \mathrm{~B}$ shows that there is a correlation between the abundances measured in $\mathrm{AD}$ and control CSF samples, as the points fall close to the diagonal. However, when considering the whole data sets, the patterns for $\mathrm{A} \beta(1-40)$ and $\mathrm{A} \beta(1-42)$ fibrils are different. For the $\mathrm{A} \beta(1-40)$ samples (Figure $5 \mathrm{~A}$ ), the points are evenly distributed around the diagonal line. For the $\mathrm{A} \beta(1-$ 42) samples (Figure 5B), on the other hand, the majority of the identified proteins end up above the diagonal (meaning that they are enriched in AD CSF), while the proteins with the highest overall abundances instead seem to be enriched in the control samples. This feature is even more obvious when comparing the ratio between the abundances in $\mathrm{AD}$ and control samples (on a $\log _{2}$ scale, Figure $5 \mathrm{C}, \mathrm{D}$ ). In $\mathrm{A} \beta(1-40$ ) samples, $49 \%$ of the proteins are enriched in the $\mathrm{AD} C S F$ samples while the corresponding number for $\mathrm{A} \beta(1-42)$ is $87 \%$.

Although these findings are intriguing, the results should be interpreted with caution as significant differences were only found for a few proteins (see above). Moreover, the mechanisms that could give rise to the observed effect are not clear. The most obvious explanations can be rejected. If there were higher total protein concentrations in the $\mathrm{AD}$ samples, we would expect to see similar trends independent of the origin of the amyloid fibrils. The same line of arguments 
holds for explanations involving the pre-existence of amyloid aggregates in the $\mathrm{AD} C \mathrm{CSF}$ samples. If the difference instead were due to higher effective concentration of $A \beta(1-42)$ fibrils compared to $\mathrm{A} \beta(1-40)$ fibrils (i.e., more available binding sites either through a larger amount of fibrils or a different morphology), we would expect to see more binding also for the control samples. Nevertheless, the results show that the two investigated $\mathrm{A} \beta$ variants gives distinct interactome responses.

We also investigated if there is a correlation between the $\mathrm{A} \beta(1-40)$ and $\mathrm{A} \beta(1-42)$ data in terms of in which type of CSF samples the proteins are enriched. The logarithmic abundance ratios for the two $\mathrm{A} \beta$ variants are compared in Figure 5E. The majority of proteins are found to be anticorrelated and found in the lower right quadrant, which is not surprising considering the graphs shown in Figure 5C,D. However, most of the points with the largest root-mean-square (RMS) are found to be enriched in $\mathrm{AD}$ CSF samples for both $\mathrm{A} \beta(1-40)$ and $\mathrm{A} \beta(1-42)$. These include, e.g., vitamin $\mathrm{K}-$ dependent protein, growth arrest-specific protein 6 , and alpha2-HS-glycoprotein. The full list of proteins in each quadrant is found in SI Table S9.

Architecture of Plaque Particles. Finally, we investigated if the generated data could provide information about how the early plaque particles are assembled. We hypothesize that for a protein that interacts directly with $\mathrm{A} \beta$ amyloid fibrils we should observe a correlation between the observed abundance of this protein and the abundance of $\mathrm{A} \beta$ in the investigated samples. The correlation might not be perfect because other proteins can affect the binding directly (e.g., as competing interaction partners) or indirectly (e.g., occupying the same binding sites on the amyloid structure). It will also depend on the initial level of the protein in the CSF samples. Nevertheless, we computed the coefficient of determination $\left(R^{2}\right)$ for the correlation with $\mathrm{A} \beta$ abundance for all proteins, and we found that about one-third of the proteins have $R^{2}$ values above 0.7 , while one-third have values below 0.1 (Figure 6A). Hence, it is unlikely that all identified proteins bind directly to $\mathrm{A} \beta$. Considering the observed differences between amyloid fibrils of $\mathrm{A} \beta(1-40)$ and $\mathrm{A} \beta(1-42)$, we decided to analyze the data for each type amyloid aggregate separately. We computed the pairwise correlations for all the identified proteins and found that all proteins (but one) display at least one correlation with a $R^{2}$ value higher than 0.69 and 0.64 for $\mathrm{A} \beta(1-40)$ and $\mathrm{A} \beta(1-$ $42)$, respectively. The only exception is prothymosin alpha, which is also the protein with the lowest overall abundance. Hence, the correlation analysis suggests that this might be a false positive. Using the values 0.69 and 0.64 for $\mathrm{A} \beta(1-40)$ and $A \beta(1-42)$, respectively, as cut-offs, we constructed models for a layered architecture of the multiprotein aggregates (Figure 6B). In these models, proteins with high correlations with $\mathrm{A} \beta$ were assumed to interact directly with $\mathrm{A} \beta$ in the first layer. Then, all proteins with a high correlation to at least one protein in the first layer were defined to constitute the second layer and so on. The outcome of this analysis depends on the cutoff values, with an increasing number of proteins ending up outside the ten first layers if the cutoff is increased. With the employed cut off values, 53 and 59 proteins are found to bind directly (i.e., the first layer) to $\mathrm{A} \beta(1-40)$ and $\mathrm{A} \beta(1-42)$, respectively, and all proteins (except prothymosin alpha as mentioned) are included within $4(\mathrm{~A} \beta 1-40)$ or $5(\mathrm{~A} \beta 1-42)$ layers.
We can observe some differences when comparing the layer compositions for $\mathrm{A} \beta(1-40)$ and $\mathrm{A} \beta(1-42)$. Most of the differences reflect moving a protein from one layer to the adjacent layer (SI Table S10). This could be subtle effects of, e.g., the employed cutoff or the relative amounts of different binding partners present in the multiprotein complexes. However, a change from the direct binding layer to layers further out could indeed indicate processes that may be of pathological relevance. We note, for instance, that the complement-related proteins seem to have a higher degree of direct binding to $\mathrm{A} \beta(1-42)$ than for the $\mathrm{A} \beta(1-40)$ fibrils. Functional analysis (GO) of the layers is presented in SI Tables S11-S13. Although this data should be interpreted with caution (as it is still a crude model), we note that all proteins annotated with amyloid- $\beta$ binding in GO molecular function are found in the first layer.

As a comparison, we also analyzed the protein interaction network by STRING ${ }^{41}$ analysis. The generated network with color-coding from our multilayer models is shown in SI Figures S4 and S5. It is not obvious what to expect from this comparison, in particular, since the STRING interaction analysis does not distinguish native interactions from those involving the amyloid structure of $\mathrm{A} \beta$. However, we note that $\mathrm{A} \beta$ (APP) appears at a very central position in the network and is surrounded by several red nodes (indicating direct binding to $\mathrm{A} \beta$ in our model). We also find that prothymosin alpha, the potential false positive mentioned above, ends up with no connections to the network. Moreover, the occurrence of highly connected networks suggest that it is plausible that many of the binding proteins could end up in the multiprotein aggregates due to secondary interactions (i.e., not direct binding to the amyloid fibrils). In the absence of experimental validation, the molecular details of the models should not be overinterpreted, but they propose that proteins may be incorporated in the deposits in different ways, which could affect their roles in the pathology.

\section{CONCLUSIONS}

In order to bring new light on the network of protein-protein interactions related to $\mathrm{A} \beta$ amyloid fibrils, we used and further developed an FC-based methodology to isolate multiprotein assemblies. We demonstrate its applicability for quantitative proteomics and show that the obtained results are complementary to the data from pull-down assays. The quantitative data allows us to analyze and compare the composition of the multiprotein aggregates based on different $\mathrm{A} \beta$ variants as well as the origin of CSF samples, and we observe distinct interactome responses for amyloid aggregates formed by $\mathrm{A} \beta(1-40)$ and $\mathrm{A} \beta(1-42)$, respectively. Functional analysis of the binding proteins identified several connections to known pathological processes of $\mathrm{AD}$. Moreover, we demonstrate how the generated results could be used to build models of the architecture of multiprotein amyloid aggregates. Our data provide a first glimpse of this architecture, although the modeling approach needs further refinement and experimental validation. Taken together, we believe this work points out a new direction for the research aimed at understanding the assembly of protein inclusions involved in amyloid disorders. The developed method can easily be applied to a variety of experimental setups with different amyloid proteins, different biological samples, different fluorescence probes, and/or different incubation conditions and thereby lay the foundation for improved understanding of the biochemical processes 
leading to the formation of senile plaques as well as other protein deposits associated with neurodegeneration.

\section{MATERIALS AND METHODS}

Materials. Human serum (single normal healthy donor) was purchased from $3 \mathrm{H}$ Biomedical AB (Uppsala, Sweden). CSF samples were obtained from the Clinical Neurochemical Laboratory (Sahlgrenska University Hospital, Gothenburg, Sweden). CSF samples were from patients who sought medical advice because of cognitive impairment. Detailed information on the samples is shown in the Supporting Information Table S2. Lyophilized recombinant $\mathrm{A} \beta(1-40)$ and $\mathrm{A} \beta(1-42)$ peptides were purchased from rPeptide (Watkinsvill, GA, USA). LCOs were kindly provided by Peter Nilsson (Linköping University, Sweden).

Preparation of Amyloid Aggregates. $\mathrm{A} \beta$ peptide samples were prepared in sodium phosphate buffer $\mathrm{pH} 7.4$ as described in ref 42 . Amyloid fibrils were obtained by incubating the peptide samples with a concentration of $1 \mathrm{mg} / \mathrm{mL}$ at $37^{\circ} \mathrm{C}$ with agitation (300 rpm) for 48 h. Fibril formation was confirmed by ThT fluorescence, AFM imaging, and far-UV CD spectroscopy. The amyloid fibril samples were stored at $4{ }^{\circ} \mathrm{C}$ during the complete set of experiments.

Pull-Down Assay. The amyloid fibrils were coupled to M-280 tosyl-activated Dynabeads (Invitrogen) as described in Rahman et al. ${ }^{14}$ M-280 tosyl-activated Dynabeads coated with glycine were used as control. ${ }^{14}$ For capturing proteins from human serum, $0.5 \mathrm{mg}$ of beads coated with $\mathrm{A} \beta$ fibrils was added to $150 \mu \mathrm{L}$ serum. The samples were incubated for $1 \mathrm{~h}$ at $37^{\circ} \mathrm{C}$ and washed three times with PBS buffer ( $\mathrm{pH} 7.4$, with $0.1 \%$ Tween-20). The bound proteins were eluted in $12 \mu \mathrm{L}$ SDS-PAGE Laemmli buffer (Bio Rad) supplemented with $50 \mathrm{mM}$ 1,4-dithiothreitol (DTT from VWR) and heated to 70 ${ }^{\circ} \mathrm{C}$ for $10 \mathrm{~min}$. The eluted samples were run on SDS-PAGE MiniProtean 4-20\% gradient gels from Bio-Rad. The gels were stained using AcquaStain (Lubio science, Zürich, Switzerland). Whole gel lanes, except for the regions containing $\mathrm{A} \beta$ (below $10 \mathrm{kDa}$ ), were extracted and analyzed by MS.

Flow Cytometry. Human serum was diluted 1:3 in PBS buffer $\mathrm{pH}$ 7.4 , and $30 \mu \mathrm{g}$ of $\mathrm{A} \beta$ fibrils was added to a final volume of $500 \mu \mathrm{L}$. The samples were incubated at $37{ }^{\circ} \mathrm{C}$ temperature for $30 \mathrm{~min}$. ThS (Sigma) was added to a final concentration of $10 \mu \mathrm{M}$ and samples were incubated at $37{ }^{\circ} \mathrm{C}$ for $10 \mathrm{~min}$. For the sorting experiments with LCOs, samples were prepared as for ThS but with a final LCO concentration of $1.5 \mu \mathrm{M}$ LCO (p-FTAA, q-FTAA-CN, or bTVBT2). For CSF samples, $20 \mu \mathrm{g}$ of $\mathrm{A} \beta$ fibrils and p-FTAA corresponding to $1.5 \mu \mathrm{M}$ final concentration were added to CSF to achieve a final volume of $500 \mu \mathrm{L}$. Isolation of multiprotein aggregates was performed at room temperature using a MoFlo Astrios EQ (Beckman Coulter).

Mass Spectrometry and Data Analysis. Protein concentrations were determined using a BCA kit from Pierce. The isolated samples were reduced, alkylated, and trypsin digested and thereafter analyzed by liquid chromatography and electrospray mass spectrometry. Quantitative data for the CSF samples were obtained using TMT10plex labeling. Proteins were identified from the SwissProt database (HUMAN) using Mascot ver. 2.5.1 (MatrixScience Ltd., UK) database search engine. For qualitative analysis of serum samples, the list of hits was filtered to remove all entries with only a single peptide identified and all keratins (contaminations). Then, a threshold was set for each sample to achieve a false discovery rate (FDR) of less than 3\%. Data with the TMT-labeled samples were analyzed on Proteome Discoverer ver. 2.2 (Thermo Scientific) using Mascot ver. 2.5.1 (MatrixScience Ltd., UK) database search engine. Keratins (contamination) were removed. The abundance was set to zero for proteins that were not detected in a specific sample, and the abundances were normalized using the abundance of $\mathrm{A} \beta$ (APP) in each sample.

Data Analysis. $p$-Values were calculated using the Student's $t$-test. For each protein, the differences in abundances of $\mathrm{AD}$ and control CSF samples were analyzed in terms of relative changes calculated as $\log _{2}$ (Abundance in $\mathrm{AD} /$ Abundance in control). GO annotations for the identified proteins were extracted from the UniProt database
(January 2019). The amino acid sequences from the Uniprot entries were used to predict the $\mathrm{pI}$ (from Proteome Discoverer ver. 2.2), charge at neutral $\mathrm{pH}$ (Expasy ProtParam), GRAVY (Expasy ProtParam), intrinsic solubility at $\mathrm{pH} 7\left(\mathrm{CamSol}^{43}\right)$, and the propensity of amyloid aggregation (TANGO, ${ }^{44,45} \mathrm{pH} \mathrm{7,37}{ }^{\circ} \mathrm{C}$, ionic strength $=0.02 \mathrm{M}$, concentration $=1 \mathrm{M}$ ). Pairwise correlations between the protein abundances were computed using Matlab R2014b (MathWorks). STRING analysis ${ }^{41}$ was performed using the web interface (string-db.org, ver. 11.0, 2019-08-27).

\section{ASSOCIATED CONTENT}

\section{(s) Supporting Information}

The Supporting Information is available free of charge at https://pubs.acs.org/doi/10.1021/acschemneuro.0c00110.

Detailed materials and methods, biophysical characterization of $\mathrm{A} \beta$ amyloid fibrils, representative $\mathrm{FC}$ fluorescence intensity histograms of CSF samples, correlation analysis between protein abundance and selected physicochemical properties, STRING proteinprotein interaction network analysis, correlations between APP abundance and average protein abundance and between APP abundance and the A $\beta$ concentration in the CSF samples. Proteins identified in serum samples, information on analyzed CSF samples, GO functional analysis of all proteins, the most abundant proteins and of the proteins enriched in specific samples, positions of individual proteins in Figure $4 \mathrm{e}$, proteins components in the layers of the structural model, GO functional analysis of the layers in the structural models. (PDF)

Comparison of FC and pull-down methods with serum-first batch (XLSX)

Comparison of FC and pull-down methods with serum-second batch (XLSX)

Identified proteins in CSF (XLSX)

Properties of the identified proteins (XLSX)

Pairwise correlations (XLSX)

\section{AUTHOR INFORMATION}

\section{Corresponding Author}

Christofer Lendel - Department of Chemistry, KTH Royal

Institute of Technology, Stockholm SE-100 44, Sweden;

다이.org/0000-0001-9238-7246; Email: lendel@kth.se

\section{Authors}

Himanshu Chaudhary - Department of Chemistry, KTH Royal Institute of Technology, Stockholm SE-100 44, Sweden

Sebastian W. Meister - Department of Protein Science, KTH Royal Institute of Technology, Stockholm SE-100 44, Sweden

Henrik Zetterberg - Department of Psychiatry and Neurochemistry, Institute of Neuroscience and Physiology, the Sahlgrenska Academy at the University of Gothenburg, Mölndal SE-413 90, Sweden; Clinical Neurochemistry Laboratory, Sahlgrenska University Hospital, Mölndal SE-413 90, Sweden; Department of Neurodegenerative Disease, UCL Institute of Neurology, London WC1N 3BG, United Kingdom; UK Dementia Research Institute at UCL, London WC1N 3BG, United Kingdom

John Löfblom - Department of Protein Science, KTH Royal Institute of Technology, Stockholm SE-100 44, Sweden; (1) orcid.org/0000-0001-9423-0541

Complete contact information is available at:

https://pubs.acs.org/10.1021/acschemneuro.0c00110 


\section{Author Contributions}

H.C. and S.W.M. contributed equally. C.L. conceived of the idea and designed the study together with H.C., S.W.M., and J.L. H.C., S.W.M., and C.L. carried out experiments and analyzed data. H.Z. provided CSF samples and background information on these samples. All authors contributed to the writing of the manuscript.

\section{Notes}

The authors declare no competing financial interest.

\section{ACKNOWLEDGMENTS}

We are grateful to Peter Nilsson (Linköping University) for providing the LCO probes. Protein identification and quantification were carried out by the Proteomics Biomedicum core facility at Karolinska Institutet, Stockholm, Sweden (https://ki.se/en/mbb/proteomics-biomedicum). We thank Akos Vegvari for his helpful assistance. This work was supported by the Swedish Alzheimer Foundation (grants AF544641, AF-640331, AF-733821 to C.L.) and the Swedish Research Council (grant 2016-03952 to C.L.). H.Z. is a Wallenberg Academy Fellow supported by grants from the Swedish Research Council (2018-02532), the European Research Council (681712), Swedish State Support for Clinical Research (ALFGBG-720931), and the UK Dementia Research Institute at UCL.

\section{REFERENCES}

(1) Chiti, F., and Dobson, C. M. (2006) Protein misfolding, functional amyloid, and human disease. Annu. Rev. Biochem. 75, 333366.

(2) Querfurth, H. W., and LaFerla, F. M. (2010) Alzheimer's disease. N. Engl. J. Med. 362, 329-344.

(3) Cupino, T. L., and Zabel, M. K. (2014) Alzheimer's silent partner: cerebral amyloid angiopathy. Transl. Stroke Res. 5, 330-337.

(4) Armstrong, R. A., Lantos, P. L., and Cairns, N. J. (2008) What determines the molecular composition of abnormal protein aggregates in neurodegenerative disease? Neuropathology 28, 351-365.

(5) Stewart, K. L., and Radford, S. E. (2017) Amyloid plaques beyond A: a survey of the diverse modulators of amyloid aggregation. Biophys. Rev. 9, 405-419.

(6) Drummond, E., Nayak, S., Faustin, A., Pires, G., Hickman, R. A., Askenazi, M., Cohen, M., Haldiman, T., Kim, C., Han, X., Shao, Y., Safar, J. G., Ueberheide, B., and Wisniewski, T. (2017) Proteomic differences in amyloid plaques in rapidly progressive and sporadic Alzheimer's disease. Acta Neuropathol. 133, 933-954.

(7) Abraham, C. R., Selkoe, D. J., and Potter, H. (1988) Immunochemical identification of the serine protease inhibitor 1antichymotrypsin in the brain amyloid deposits of Alzheimer's disease. Cell 52, 487-501.

(8) Kalaria, R. N., Golde, T., Kroon, S. N., and Perry, G. (1993) Serine-protease inhibitor antithrombin-III and its messenger-RNA in the pathogenesis of Alzheimers-disease. Am. J. Pathol. 143, 886-893.

(9) Nakamura, Y., Takeda, M., Suzuki, H., Hattori, H., Tada, K., Hariguchi, S., Hashimoto, S., and Nishimura, T. (1991) Abnormal distribution of cathepsins in the brain of patients with Alzheimersdisease. Neurosci. Lett. 130, 195-198.

(10) Navarro, A., del Valle, E., Astudillo, A., del Rey, C. G., and Tolivia, J. (2003) Immunohistochemical study of distribution of apolipoproteins $\mathrm{E}$ and $\mathrm{D}$ in human cerebral amyloid deposits. Exp. Neurol. 184, 697-704.

(11) Liao, L., Cheng, D., Wang, J., Duong, D. M., Losik, T. G., Gearing, M., Rees, H. D., Lah, J. J., Levey, A. I., and Peng, J. (2004) Proteomic characterization of postmortem amyloid plaques isolated by laser capture microdissection. J. Biol. Chem. 279, 37061-37068.
(12) Xiong, F., Ge, W., and Ma, C. (2019) Quantitative proteomics reveals distinct composition of amyloid plaques in Alzheimer's disease. Alzheimer's Dementia 15, 429-440.

(13) Hadley, K. C., Rakhit, R., Guo, H., Sun, Y., Jonkman, J. E., McLaurin, J., Hazrati, L. N., Emili, A., and Chakrabartty, A. (2015) Determining composition of micron-scale protein deposits in neurodegenerative disease by spatially targeted optical microproteomics. eLife 4, No. e09579.

(14) Rahman, M. M., Zetterberg, H., Lendel, C., and Härd, T. (2015) Binding of human proteins to amyloid-m protofibrils. ACS Chem. Biol. 10, 766-774.

(15) Olzscha, H., Schermann, S. M., Woerner, A. C., Pinkert, S., Hecht, M. H., Tartaglia, G. G., Vendruscolo, M., Hayer-Hartl, M., Hartl, F. U., and Vabulas, R. M. (2011) Amyloid-like aggregates sequester numerous metastable proteins with essential cellular functions. Cell 144, 67-78.

(16) Juhl, D. W., Risor, M. W., Scavenius, C., Rasmussen, C. B., Otzen, D., Nielsen, N. C., and Enghild, J. J. (2019) Conservation of the amyloid interactome across diverse fibrillar structures. Sci. Rep. 9, 3863.

(17) Nandakumar, A., Xing, Y., Aranha, R. R., Faridi, A., Kakinen, A., Javed, I., Koppel, K., Pilkington, E. H., Purcell, A. W., Davis, T. P., Faridi, P., Ding, F., and Ke, P. C. (2020) Human plasma protein corona of Ao amyloid and its impact on islet amyloid polypeptide cross-Seeding. Biomacromolecules 21, 988-998.

(18) Pilkington, E. H., Gustafsson, O. J. R., Xing, Y. T., HernandezFernaud, J., Zampronio, C., Kakinen, A., Faridi, A., Ding, F., Wilson, P., Ke, P. C., and Davis, T. P. (2018) Profiling the serum protein corona of fibrillar human islet amyloid polypeptide. ACS Nano 12, 6066-6078.

(19) Lynch, I., Cedervall, T., Lundqvist, M., Cabaleiro-Lago, C., Linse, S., and Dawson, K. A. (2007) The nanoparticle-protein complex as a biological entity, a complex fluids and surface science challenge for the 21 st century. Adv. Colloid Interface Sci. 134-135, $167-174$.

(20) Ezzat, K., Pernemalm, M., Pålsson, S., Roberts, T. C., Järver, P., Dondalska, A., Bestas, B., Sobkowiak, M. J., Levanen, B., Sköld, M., Thompson, E. A., Saher, O., Kari, O. K., Lajunen, T., Ekström, E. S., Nilsson, C., Ishchenko, Y., Malm, T., Wood, M. J. A., Power, U. F., Masich, S., Linden, A., Sandberg, J. K., Lehtiö, J., Spetz, A. L., and El Andaloussi, S. (2019) The viral protein corona directs viral pathogenesis and amyloid aggregation. Nat. Commun. 10, 2331.

(21) Blennow, K., Hampel, H., Weiner, M., and Zetterberg, H. (2010) Cerebrospinal fluid and plasma biomarkers in Alzheimer disease. Nat. Rev. Neurol. 6, 131-144.

(22) Palmqvist, S., Zetterberg, H., Blennow, K., Vestberg, S., Andreasson, U., Brooks, D. J., Owenius, R., Hägerström, D., Wollmer, P., Minthon, L., and Hansson, O. (2014) Accuracy of brain amyloid detection in clinical practice using cerebrospinal fluid l-amyloid 42: a cross-validation study against amyloid positron emission tomography. JAMA Neurol. 71, 1282-1289.

(23) Trieschmann, L., Navarrete Santos, A., Kaschig, K., Torkler, S., Maas, E., Schatzl, H., and Bohm, G. (2005) Ultra-sensitive detection of prion protein fibrils by flow cytometry in blood from cattle affected with bovine spongiform encephalopathy. BMC Biotechnol. 5, 26.

(24) Yang, Y., Keene, D., Peskind, E. R., Galasko, D. R., Hu, S.-C., Cudaback, E., Wilson, A. M., Li, G., Yu, C.-E., Montine, K. S., Zhang, J., Baird, G. S., Hyman, B. T., and Montine, T. J. (2015) Cerebrospinal fluid particles in Alzheimer disease and Parkinson disease. J. Neuropathol. Exp. Neurol. 74, 672-687.

(25) Madasamy, S., Chaudhuri, V., Kong, R., Alderete, B., Adams, C. M., Knaak, T. D., Ruan, W., Wu, A. H., Bigos, M., and Amento, E. P. (2015) Plaque array method and proteomics-based identification of biomarkers from Alzheimer's disease serum. Clin. Chim. Acta 441, 79-85.

(26) Cohen, S. I., Linse, S., Luheshi, L. M., Hellstrand, E., White, D. A., Rajah, L., Otzen, D. E., Vendruscolo, M., Dobson, C. M., and Knowles, T. P. (2013) Proliferation of amyloid- 42 aggregates occurs 
through a secondary nucleation mechanism. Proc. Natl. Acad. Sci. U. S. A. 110, 9758-9763.

(27) Meisl, G., Yang, X., Hellstrand, E., Frohm, B., Kirkegaard, J. B., Cohen, S. I., Dobson, C. M., Linse, S., and Knowles, T. P. (2014) Differences in nucleation behavior underlie the contrasting aggregation kinetics of the A 40 and A442 peptides. Proc. Natl. Acad. Sci. U. S. A. 111, 9384-9389.

(28) Rahman, M. M., Westermark, G. T., Zetterberg, H., Härd, T., and Sandgren, M. (2018) Protofibrillar and fibrillar amyloid-m binding proteins in cerebrospinal fluid. J. Alzheimer's Dis. 66, 10531064.

(29) Klingstedt, T., and Nilsson, K. P. (2012) Luminescent conjugated poly- and oligo-thiophenes: optical ligands for spectral assignment of a plethora of protein aggregates. Biochem. Soc. Trans. 40, 704-710.

(30) Åslund, A., Sigurdson, C. J., Klingstedt, T., Grathwohl, S., Bolmont, T., Dickstein, D. L., Glimsdal, E., Prokop, S., Lindgren, M., Konradsson, P., Holtzman, D. M., Hof, P. R., Heppner, F. L., Gandy, S., Jucker, M., Aguzzi, A., Hammarström, P., and Nilsson, K. P. R. (2009) Novel pentameric thiophene derivatives for in vitro and in vivo optical imaging of a plethora of protein aggregates in cerebral amyloidoses. ACS Chem. Biol. 4, 673-684.

(31) Bäck, M., Appelqvist, H., LeVine, H., and Nilsson, K. P. R. (2016) Anionic oligothiophenes compete for binding of X-34 but not PIB to recombinant Ae amyloid fibrils and Alzheimer's disease brainderived Ai. Chem. - Eur. J. 22, 18335-18338.

(32) Shirani, H., Appelqvist, H., Bäck, M., Klingstedt, T., Cairns, N. J., and Nilsson, K. P. R. (2017) Synthesis of thiophene-based optical ligands that selectively detect tau pathology in Alzheimer's disease. Chem. - Eur. J. 23, 17127-17135.

(33) Sipe, J. D., Benson, M. D., Buxbaum, J. N., Ikeda, S. I., Merlini, G., Saraiva, M. J., and Westermark, P. (2016) Amyloid fibril proteins and amyloidosis: chemical identification and clinical classification International Society of Amyloidosis 2016 Nomenclature Guidelines. Amyloid 23, 209-213.

(34) Paterson, R. W., Heywood, W. E., Heslegrave, A. J., Magdalinou, N. K., Andreasson, U., Sirka, E., Bliss, E., Slattery, C. F., Toombs, J., Svensson, J., Johansson, P., Fox, N. C., Zetterberg, H., Mills, K., and Schott, J. M. (2016) A targeted proteomic multiplex CSF assay identifies increased malate dehydrogenase and other neurodegenerative biomarkers in individuals with Alzheimer's disease pathology. Transl. Psychiatry 6, No. e952.

(35) Roher, A. E., Maarouf, C. L., Sue, L. I., Hu, Y., Wilson, J., and Beach, T. G. (2009) Proteomics-derived cerebrospinal fluid markers of autopsy-confirmed Alzheimer's disease. Biomarkers 14, 493-501.

(36) Bigl, M., Bruckner, M. K., Arendt, T., Bigl, V., and Eschrich, K. (1999) Activities of key glycolytic enzymes in the brains of patients with Alzheimer's disease. J. Neural Transm. 106, 499-511.

(37) Luo, J., Wärmlander, S. K., Gräslund, A., and Abrahams, J. P. (2014) Non-chaperone proteins can inhibit aggregation and cytotoxicity of Alzheimer amyloid peptide. J. Biol. Chem. 289, $27766-27775$

(38) Smith, E. R., Nilforooshan, R., Weaving, G., and Tabet, N. (2011) Plasma fetuin-A is associated with the severity of cognitive impairment in mild-to-moderate Alzheimer's disease. J. Alzheimer's Dis. 24, 327-333.

(39) Krenzlin, H., Lorenz, V., Danckwardt, S., Kempski, O., and Alessandri, B. (2016) The importance of thrombin in cerebral injury and disease. Int. J. Mol. Sci. 17, E84.

(40) Arai, T., Miklossy, J., Klegeris, A., Guo, J. P., and McGeer, P. L. (2006) Thrombin and prothrombin are expressed by neurons and glial cells and accumulate in neurofibrillary tangles in Alzheimer disease brain. J. Neuropathol. Exp. Neurol. 65, 19-25.

(41) Szklarczyk, D., Gable, A. L., Lyon, D., Junge, A., Wyder, S., Huerta-Cepas, J., Simonovic, M., Doncheva, N. T., Morris, J. H., Bork, P., Jensen, L. J., and Mering, C. (2019) STRING v11: protein-protein association networks with increased coverage, supporting functional discovery in genome-wide experimental datasets. Nucleic Acids Res. 47, D607-D613.
(42) Abelein, A., Bolognesi, B., Dobson, C. M., Gräslund, A., and Lendel, C. (2012) Hydrophobicity and conformational change as mechanistic determinants for nonspecific modulators of amyloid selfassembly. Biochemistry 51, 126-137.

(43) Sormanni, P., Aprile, F. A., and Vendruscolo, M. (2015) The CamSol method of rational design of protein mutants with enhanced solubility. J. Mol. Biol. 427, 478-490.

(44) Fernandez-Escamilla, A. M., Rousseau, F., Schymkowitz, J., and Serrano, L. (2004) Prediction of sequence-dependent and mutational effects on the aggregation of peptides and proteins. Nat. Biotechnol. 22, 1302-1306.

(45) Linding, R., Schymkowitz, J., Rousseau, F., Diella, F., and Serrano, L. (2004) A comparative study of the relationship between protein structure and -aggregation in globular and intrinsically disordered proteins. J. Mol. Biol. 342, 345-353. 